\title{
Natural history and courtship behavior in Tengella perfuga Dahl, 1901 (Araneae: Zoropsidae)
}

\author{
Rachael E. Mallis and Kelly B. Miller: Museum of Southwestern Biology, Arthropods, 1 University of New Mexico, \\ MSC03 2020, Albuquerque, New Mexico 87131: E-mail: mallis@unm.edu
}

\begin{abstract}
Tengella perfuga Dahl, 1901 is a Nicaraguan cribellate zoropsid spider found in high altitude remnant cloud forest habitats bordering coffee plantations. Since its description in 1901, and its rediscovery in 2012, almost nothing is known of its natural history, life history, courtship or web spinning behavior. Observations were made in the field, as well as in the lab. Mature female $T$. perfuga occurred in funnel webs with several knockdown lines comprised of cribellate silk, and that were typically placed between buttress roots of strangler figs or other outcropping structures, while males abandoned their webs upon adulthood to search for females. Here, we describe the life history, growth, web ontogeny, courtship and reproductive behaviors, as well as silk use of this spider for the first time. There are 11-12 instars to reach adulthood and cribellate silk did not appear in juvenile webs until the eighth instar. Interestingly, orbicularian-like behaviors were observed in the initial appearance of cribellate silk lines in the juvenile web in a spiral-like pattern. Males exhibited positive allometric growth in Leg I from penultimate to adult instars, which likely plays an important role in courtship; this included strumming the sheet, stroking the female and depositing a thin 'bridal veil' of silk on the female. Virgin females had 'mating plugs' prior to exposure to males. This suggests that $T$. perfuga may be an interesting species with which to further examine sexual evolution and female choice.
\end{abstract}

Keywords: Web ontogeny, growth, cribellate silk, reproduction

Tengella perfuga Dahl, 1901 is the type species for the genus Tengella Dahl, 1901, which is the type genus for the recently reassigned family Tengellidae Dahl, 1908 (= Zoropsidae Bertkau, 1882 (Polotow et al. 2015)). They are medium to large cribellate spiders and little is known about their natural history, courtship behavior, feeding behavior and web ontogeny (Fig. 1, Platnick 2009; Leister et al. 2013). While spiders of the genus Tengella are distributed across various habitats in Central America, from caves in Mexico to tropical lowland forests in Panama, T. perfuga is limited to high altitude remnant cloud forest habitats bordering coffee plantations in northwestern Nicaragua and Honduras (Leister et al. 2013, S. Longhorn, pers. comm.). However, the potential sister species, Tengella radiata (Kulczyński, 1909), is widespread and found in various high and low elevation tropical forests, coffee plantations and developed sites from Honduras south to Panama (Leister et al. 2013). The phylogenetic placement of $T$. perfuga has long been uncertain in large part due to its use of cribellate silk (Fig. 1). Cribellate silk is produced from glands that open on a plate-like structure, the cribellum, derived from the ancestrally lost anterior median spinnerets (Pechmann et al. 2010). Cribellate silk production also requires a comb (calamistrum) on the fourth leg which primes the silk glands and combs out the loops of fibrils (Hawthorn \& Opell 2002). Use of this type of silk in Tengella is surprising, given the developmental investment and metabolic costs to maintaining the cribellum and calamistrum (Blackledge et al. 2009a), and that this trait is typically found in older spider lineages, whereas Tengella is part of a more recently evolved clade, the majority of whose members have evolved the loss of silk use as a foraging tool (Raven \& Stumkat 2003, 2005; Griswold et al. 2005; Spagna \& Gillespie 2008; Blackledge et al. 2009a, b; Agnarsson et al. 2013; Polotow et al. 2015). As such, $T$. perfuga is at the crux of important phylogenetic questions about the evolution of silk use in spiders, particularly within the RTA clade to which both Tengella (zoropsids) and their sister group Lycosoidea belong (Griswold et al. 2005; Polotow et al. 2015).

One approach to understanding the evolutionary history of silk use is to observe web ontogeny. Early instar webs may resemble the ancestral web design or plesiomorphic traits in silk use, so understanding web ontogeny can help reconstruct evolutionary history (Eberhard 1985, 1986; Barrantes \& Madrigal-Brenes 2008; Barrantes \& Eberhard 2010). Given the recent genomic evidence of paraphyly in the Orbiculariae and the placement of $T$. perfuga within the RTA clade, a web ontogeny study becomes important as a way to behaviorally examine the evolution of silk use and orb web ancestry in this clade (Agnarsson et al. 2013; Bond et al. 2014; Fernandez et al. 2014). Orbicularian traits of silk use within the RTA clade have only recently been examined once, where the phylogenetic placement of the Psechridae, a family of cribellate pseudo-orb weavers, was moved from the Orbiculariae to the RTA clade (Agnarsson et al. 2013). This study of T. perfuga is the first study to specifically look for evidence of orbicularian behavioral traits in a member of the RTA clade.

Two previous studies were conducted on $T$. radiata and these served as a basis for the studies reported here. Tengella radiata develop to adulthood in 9-10 molts, with males having longer forelegs than females (Barrantes \& Madrigal-Brenes 2008). Webs begin as basic sheets and more complex elements are added with each instar; notably, cribellate silk does not appear until the seventh instar (Barrantes \& Madrigal-Brenes 2008). Males court females with a series of plucking the web, rocking motions and tapping to induce the female to copulate; females show some aggressive reactions to potentially unsuitable partners (Barrantes 2008). Males also exhibited a 'flub' behavior while attempting insertions, with repeated scraping motions, but successful insertion and single expansion of the hematodocha was extremely rapid when it occurred (Barrantes 2008).

The objective of this study was to learn more about these enigmatic spiders, particularly their use of cribellate silk, life history, behavior, and ontogenetic changes in web size and structure.

\section{METHODS}

Field collection and specimen sources.-Live T. perfuga adult females were collected in Nicaragua (Selva Negra, $12.9984^{\circ} \mathrm{N}$, 


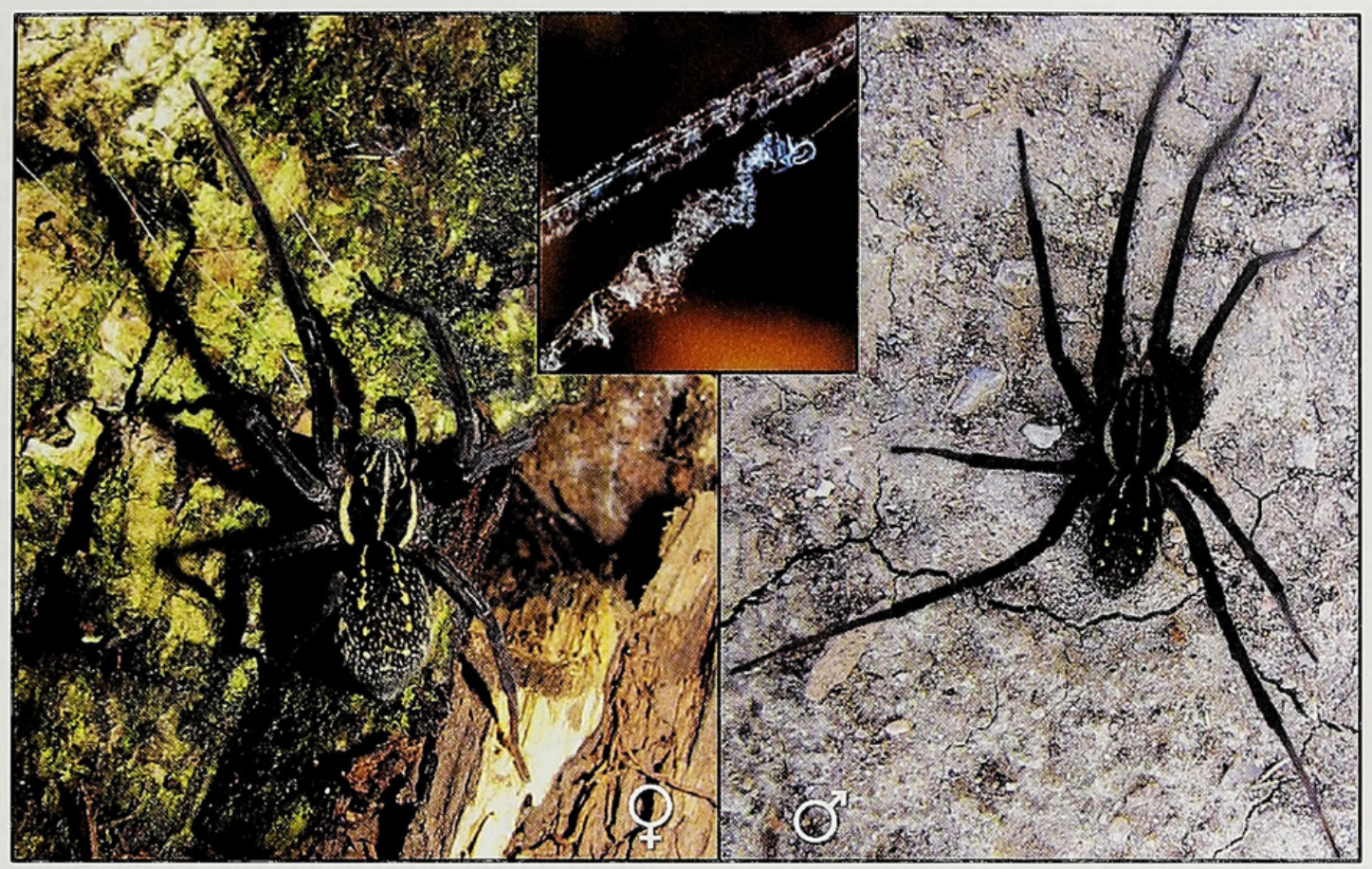

Figure 1.-Adult male (right) and female (left) Tengella perfuga, with cribellate silk from a female web (inset) (Spider whole body photos: M Leister, with R. Mallis 2012).

$85.9105^{\circ} \mathrm{W}$ ) in May 2012 (permit: DGPN / DB - $09-2012$ ), and subsequently in May 2014 (permit: DGPN / DB - 006 2014) and allowed to mate and/or lay egg sacs, giving rise to a lab-reared spider colony which at one time numbered well over 500 individuals. Many of these reached adulthood and reproduced, allowing for observations of courtship behavior, growth and web ontogeny. Observations of web structure and feeding behavior were made in the field $(n>>100)$. Most field encountered males were collected in female webs (in 2014, $n=$ 7 ; in $2012, n>15$ ) or as penultimate males in their own webs. All field-caught spiders and reared individuals are deposited in the Museum of Southwestern Biology, Division of Arthropods collection or teaching collection (MSBA $24980-24982$, 24985, 24986, 29081, 29082, 30589, 30591, 30592, 30596 $30599,30619,30621,30622,30635,30640,30642,30643)$. A complete instar series, as well as SEM specimens, from second instar to adult male and female $T$. perfuga is also deposited at the California Academy of Sciences, Department of Entomology alcohol collection. These include a few of the specimens used in the growth and web ontogeny studies.

Web ontogeny and life history.-A sub-group of approximately 50 second-instar individuals, which had recently emerged from two different egg sacs, were removed from the maternal webs and housed individually. Web ontogeny and spider growth at each instar stage were measured. Each stage is referred to by its sequential number; for example, the second instar is called 'instar 2 ' and so forth. We measured the width at widest points and the lengths of the cephalothorax, femur I, tibia I and the overall body length of recently molted individuals for each instar. Measurements were made using an Olympus SZ60 binocular dissecting scope equipped with a calibrated $10 \times$ micrometer. Images of instars and silk were taken using a Visionary Digital System (online at http://www.visionarydigital. com). We noted web dimensions and characteristics such as the appearance of cribellate silk, but the webs of older instars filled the containers in which they were housed (Gladware ${ }^{\circledR}$ storage containers, $15.5 \times 15.5 \mathrm{~cm}$ and approximately $3.5 \mathrm{~cm}$ high) and so web size was artificially limited. Webs for each instar were imaged using a Nikon Coolpix L110 camera.

Colony Maintenance: Spider habitats were Gladware ${ }^{\circledR}$ square plastic storage containers filled with a layer of EcoEarth ${ }^{\circledR}$ Similar to a study of the closely related $T$. radiata, we provided 2-4 pieces of corkwood for web attachment, rather than rocks, and a retreat option of a $2 \mathrm{~mL}$ vial, rather than a rolled-up leaf as in a previous study (Barrantes \& Madrigal-Brenes 2008). In 2012, we collected two gravid females in the field, and used 25 spiderlings from one female and 27 from the other in our study. Three groups of six additional spiderlings each were set up for observation as well to better understand conspecific tolerance, as $T$. perfuga was sometimes found at higher densities in a single site in the field. Containers were spritzed with distilled water weekly to provide moisture, and spiders were fed a steady diet of crickets ranging in size from pinheads to medium-large and fruit flies. Natural history traits such as feeding behavior and timing of molts were recorded. Containers were monitored daily for spider status and spiderlings fed twice weekly, but as they aged, feedings became once weekly to biweekly. Spiders were maintained at ambient room temperatures in the laboratory and as close to a 10:14 light:dark ratio as possible. Individuals that died of natural causes were also preserved in $70 \% \mathrm{EtOH}$ with a leg placed in $95 \% \mathrm{EtOH}$ for potential future molecular sequencing work.

Measurements: After all spiders in the colonies had completed an instar and molted, three from a pool of the two mothers offspring were randomly selected and their containers placed in a $-20^{\circ} \mathrm{C}$ freezer to preserve the web for imaging. Culled spiders were immediately removed after webs were imaged. One spider was stored in $95 \% \mathrm{EtOH}$ at $-80^{\circ} \mathrm{C}$ to preserve genetic data, and the remaining two were placed in $70 \% \mathrm{EtOH}$ and used for morphological measurements. Webs were photographed dry 


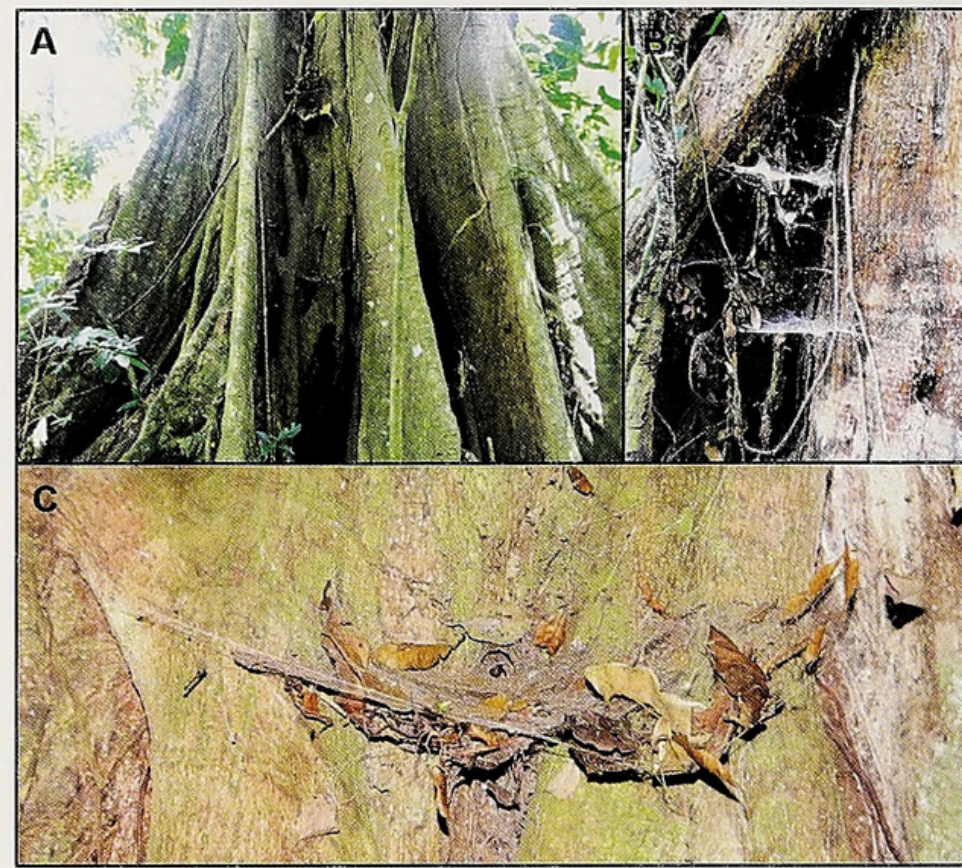

Figure $2 \mathrm{~A}-\mathrm{C}$.-Webs in the field in Nicaragua, showing variation in structure. A. Preferred habitat of strangler fig buttress roots. B. stacked webs of juveniles. C. adult female web.

and subsequently wet after being lightly spritzed with water to increase their visibility, and the presence or absence of cribellate silk and length, width and height (if applicable) measurements were taken. Webs from eighth-instar spiders were inadvertently damaged prior to measurements, but presence or absence of cribellate silk observations were still recorded.

Averages and standard deviations of morphological measurements for each instar were calculated from the pooled data per instar. To calculate the relative percent growth from instar to instar, we used the equation as in Barrantes \& MadrigalBrenes (2008): [(Tibia I InstarN - Tibia I InstarN-1)/Tibia I Instar $\mathrm{N}-1] * 100$. While much of our approach for the natural history study was inspired by Barrantes \& Madrigal-Brenes (2008), we had some differences, such as spritzing webs with water rather than corn starch and more importantly, using culled spiders for measurements, rather than rehydrating shed molts from the same individual spiders as they grew.

Courtship observations. - Using adult spiders from later generations and other field collections, as well as the remaining adults from the web ontogeny study, non-related pairs were randomly assigned for mating ( $n=35$ documented observations; 24 initial pairings, and 11 subsequent interactions). All females were virgin and well fed prior to introduction of the males. Males were placed onto female webs and courtship encounters were video recorded and behaviors noted. Males were removed after copulating once or after rejection by the female in order to reduce the chances of mortality $(n=24)$. They were secondarily introduced to the same or a different non-related female to propagate the spider colony, but allowed us to observe differences in courtship behavioral patterns and acceptance $(n=11)$. Females were later allowed to lay egg sacs following successful copulations.

\section{RESULTS}

Webs in the field. $-T$. perfuga sheet webs typically had a funnel retreat either at a corner or the middle of the sheet that receded into the substrate $(n>>100)$ (Fig. 2). Sheets were typicaliy surrounded by a scaffolding of tangle or knockdown lines above and anchor lines below (Fig. 2; Leister et al. 2013). The sheets were lined with cribellate silk and the majority of knockdown lines had cribellate silk laid over them. Webs typically occurred along stream embankments, tree trunks (especially strangler figs) and between stones or wood beams on structures at high elevation cloud forest sites associated with shade coffee plantations in northern Nicaragua. Spiders were observed in the retreat or just at the retreat opening; they ran out onto the sheet to capture prey and drag it back to the retreat, as we also recorded in Leister et al. (2013).

A variety of web locations were noted in the field, with some adult female webs appearing in unexpected places, like a hole in a trail sign on a tree or across the span of an empty bell tower of a stone chapel. Some webs had egg sacs or second or third instar spiderlings in the retreat (Fig. 3A, B). The egg sacs were covered with pieces of the surrounding substrate, from bark to soil to leaves (Fig. 3B). Egg sac production was not observed in the field. At two less disturbed sites, webs were

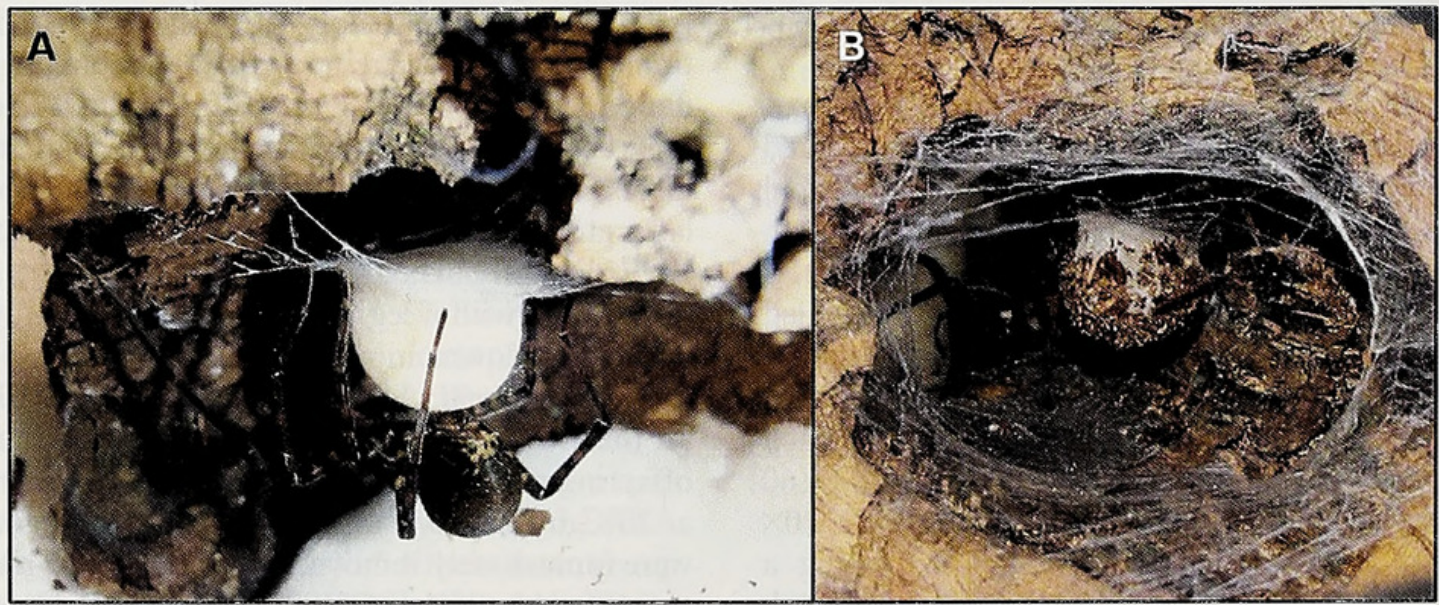

Figure 3A-B.-Egg sac construction and camouflage. A. Female silking over egg sac after depositing the eggs. B. Female guarding a camouflaged egg sac. 


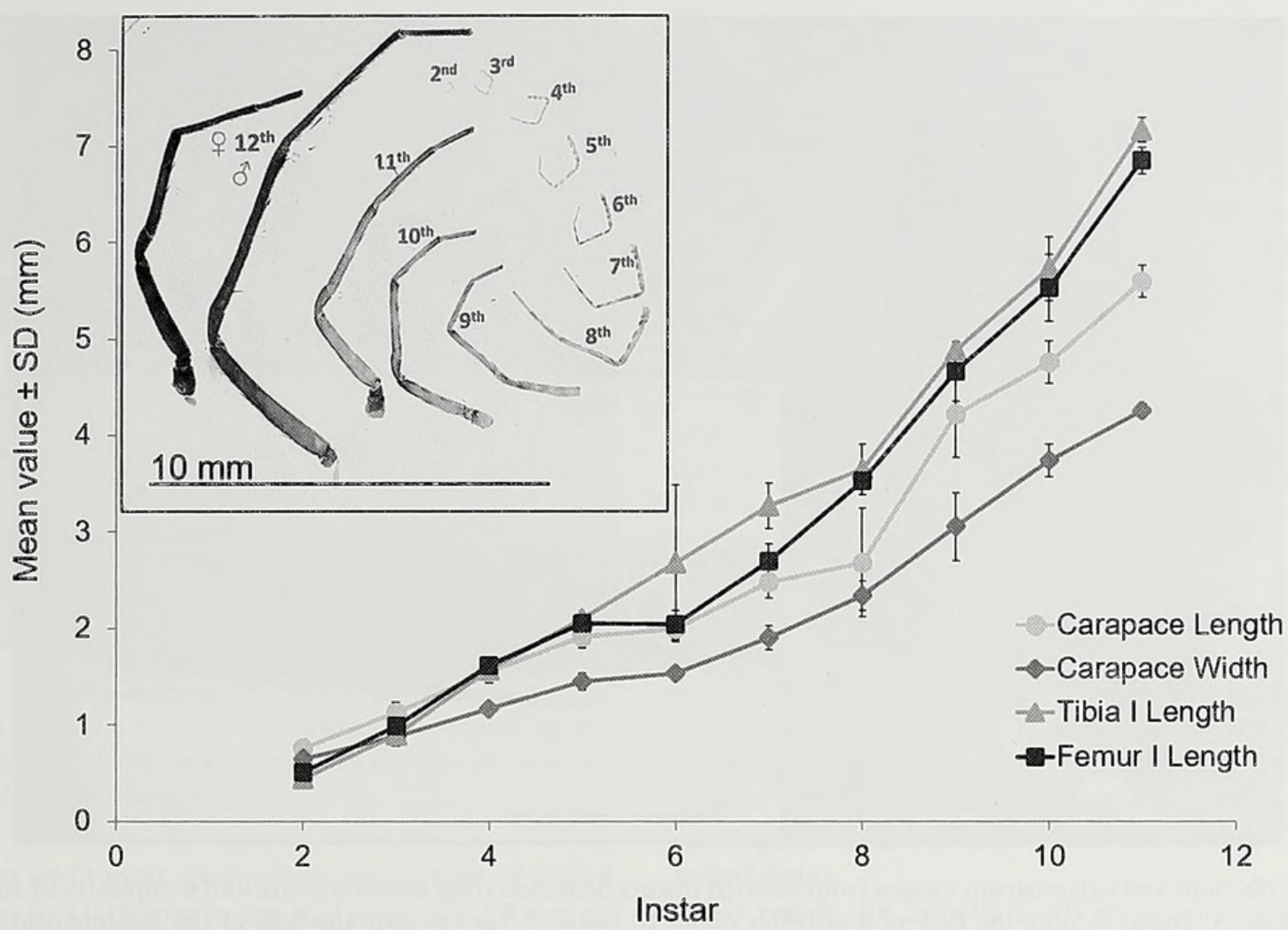

Figure 4.- Growth from instar to instar of cephalothorax length and width, femur I and tibia I lengths. Comparison of the amount of growth in Leg I that occurs from second to twelfth instar (adulthood), as well as the allometric growth of male during the final molt (inset).

observed with commensal bugs and kleptoparasitic spiders, similar to reports for the closely related species, $T$. radiata (Eberhard et al. 1993). These web symbionts have not yet been identified.

Observations in the laboratory.-Tengella perfuga reached adulthood between 205 - 226 days and 11-12 molts after emerging from the egg sac as a second instar nymph. Females reached adulthood typically in 12, sometimes 11 instars, whereas most males reached adulthood in $10-11$ instars. For the morphological measurements and web ontogeny observations, we used males who reached adulthood in 12 instars. Female $T$. perfuga tended to be more robust than males, however the color patterning is similar (Fig. 1). Males had longer legs than females, particularly leg I (Fig. 4 inset; Leister et al. 2013). The calamistrum did not appear to be a full oval until instar 5, and the cribellum did not appear to be functional until instars 7 and 8 (see Fig. 5). Cribellate silk did not appear in the webs until the eighth instar (Figs. $6 \& 7$ ). After hatching from the egg sac, spiderlings remained with the mother in her retreat on a collectively spun 'molting web.' Once molted to the third instar, spiderlings began to disperse.

Most of the early instar webs exhibited features such as a simple sheet and clear retreat tunnel similar to those of adult webs, but were smaller and lacked cribellate silk (Fig. 6A, B). First, a tiny retreat was formed with some lines extending to form the scaffolding for the subsequent sheet (instar 3), then a sheet was filled in (instar 4). Prey capture was still successful, despite a small capture surface, and these instars grabbed prey through the retreat or sheet or ran on top of the structure to bite the prey. Knockdown lines were not observed until instars 5 and 6 (Fig. 6A, B). When cribellate silk first appeared in the webs, it was in an orb-like spiral laid out on the sheet (Fig. 7).
Ultimately, adult webs were comprised of a deep retreat into the substrate, surrounded by a broad sheet with several knockdown lines or 'scaffolding' above the sheet and retreat entrance. The majority ( $n \sim 25$ adult webs observed) of the structures were lined with cribellate silk (Figs. 2 \& 6D).

Life history: Eggs hatched in approximately 54 days $(n=2$ egg sacs). It took five days for all spiderlings to leave the egg sac. In the groups of six spiders, each spider in the group had its own retreat and shared use of the sheet. Minimal cannibalism was observed and there appeared to be tolerance for con-specifics. Development time varied. Small males were observed after 9 - 10 molts. Some females developed with less time between each of the 12 molts. Other members $(n=4)$ of the groups appeared to have arrested development in earlier instars and never reached adulthood during the nearly yearlong observational period.

Growth: Overall, from second to eleventh instar, $T$. perfuga grew by $612 \%$ relative to the body length of a second instar (Table 1). Other body parts, such as tibia I and femur I, also grew by over $1400 \%$ and $1200 \%$, respectively (Table 1; Fig. 4). There appeared to be less growth between the fifth and sixth instars and seventh and eighth instars (Table 1, Fig. 4). Because the sample size for each instar $(n=2-3)$ was small, there was no power for statistical analyses. Second instar spiders did not eat, as they still had yolk fat, and although they were able to readily walk on the mother's web, the legs appeared short for the body size (approximately 4:1 ratio of body length to tibia I length, vs. approximately $2: 1$ ratio of body length to tibia I length in penultimates). Spiders began foraging on their webs in the third instar, and this was when their overall appearance mirrored adult gestalt and pattern. Males had a greater increase in leg I length than females from 


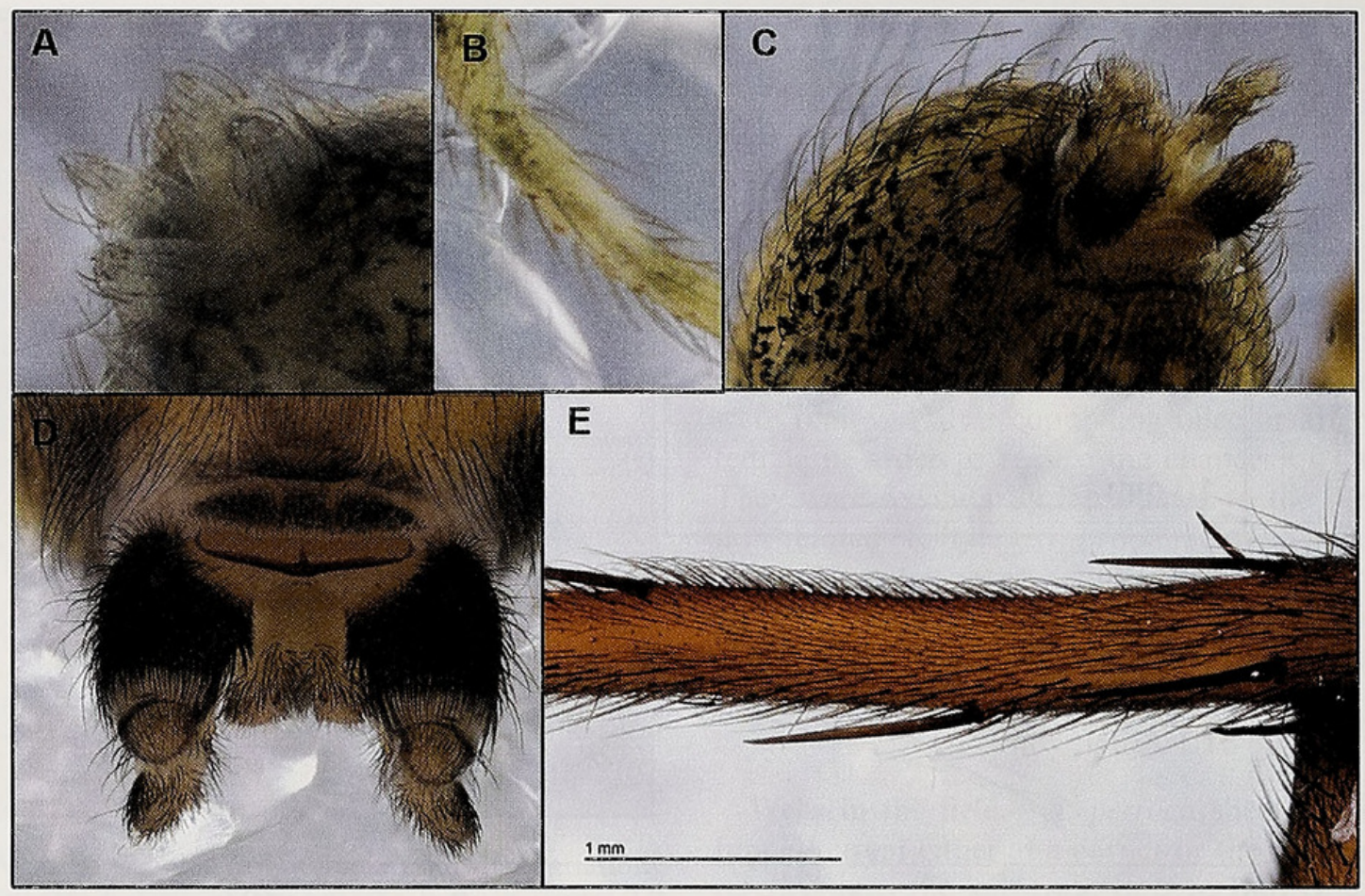

Figure 5A-E.-Cribellum and calamistrum images from selected instars demonstrating increasing size and complexity of structures, as well as potential functionality. A. Instar 2, note the lack of a cribellar plate. B. Instar 2, leg IV, note the lack of the calamistrum (however, see next image). C. Instar 3, cribellum present. D. Instar 11, cribellum (penultimate male). and E. Instar 11, oval shaped calamistrum (penultimate male).

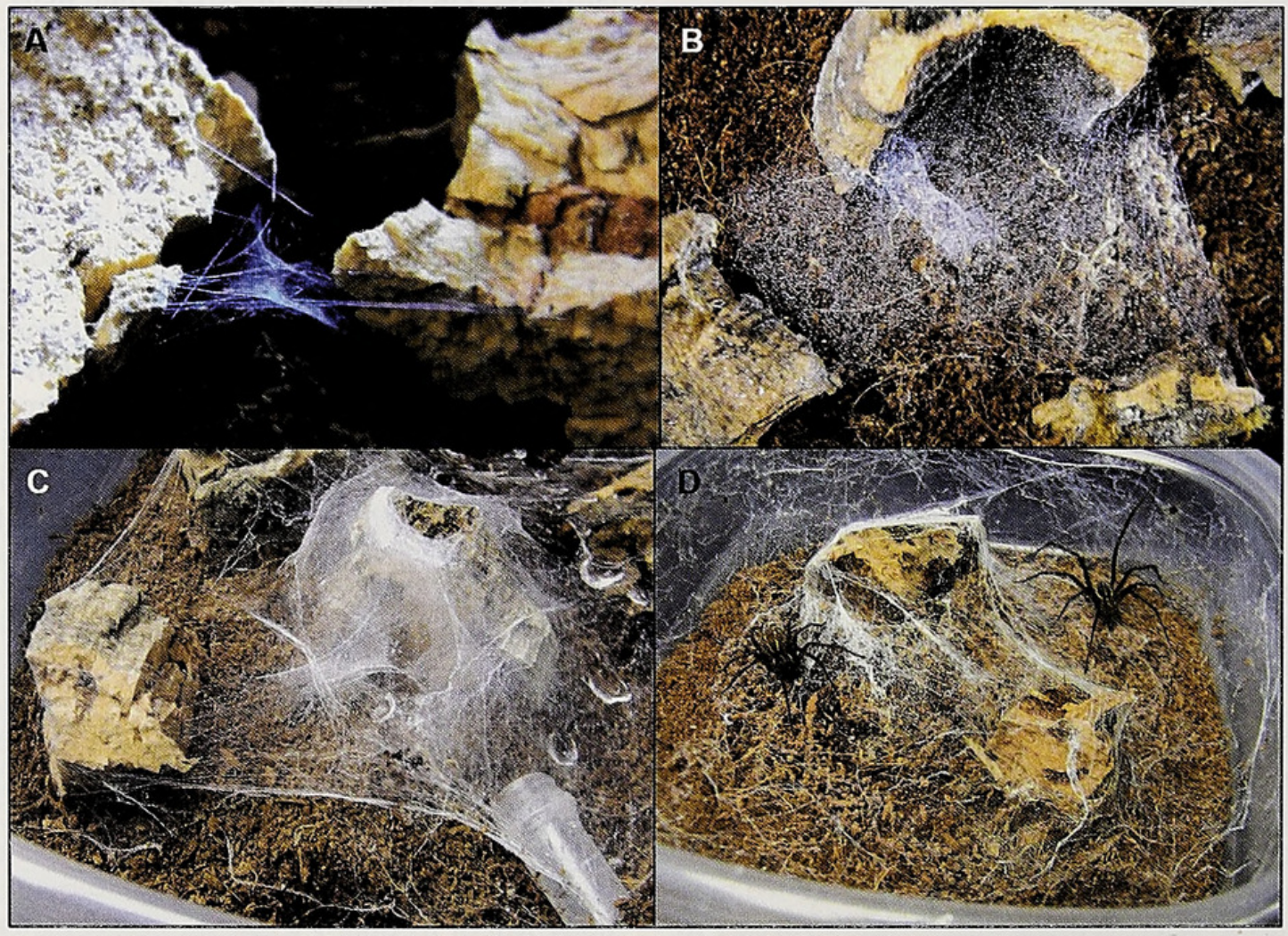

Figure 6A-D.-Web images from selected instars in the lab, demonstrating web growth and increasing complexity of structure and the presence of cribellate silk. A. Web of third instar spiderling. B. Web of fourth instar spiderling. C. Web of ninth instar spiderling. D. Web of adult female with male present (Instar 12). 


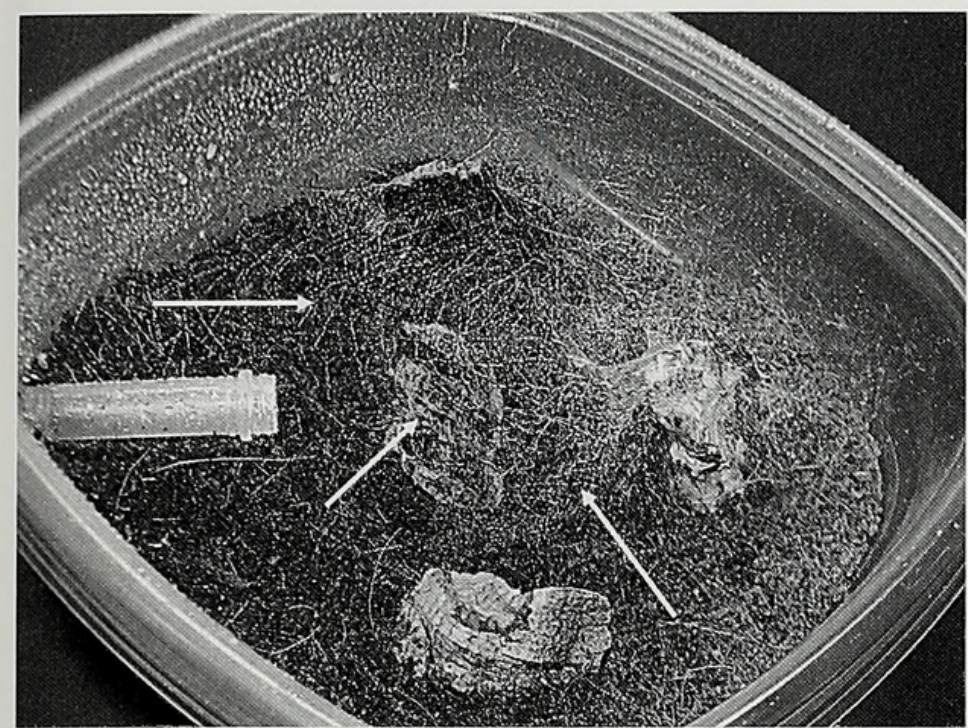

Figure 7.-The orb-like pattern, indicated by the arrows, of cribellate silk in the sheet of a juvenile, eighth instar $T$. perfuga. In this image, focus was sharpened and contrast was enhanced in order to aid in observing the spiraling cribellate lines.

the penultimate to adult molt, going from an average of tibia I length of $7.17 \mathrm{~mm}$ to $11.19 \mathrm{~mm}$ in the male versus $7.17 \mathrm{~mm}$ to $7.63 \mathrm{~mm}$ in the female, suggesting allometric growth occurred (see Fig. 4 inset, adult length values previously published in Leister et al. 2013).

Ontogeny of the cribellum, calamistrum and cribellate silk use: In mature individuals of both sexes, the cribellum was a pseudobipartite plate (Fig. 5D). There were two patches of spigots in the female, a row of setae at the anterior margin and a line of sclerotization at the posterior margin. The calamistrum was an oval patch that extended one third the length of metatarsus IV on the proximal half dorsoretrolaterally (Fig. 5E). The male cribellum was a featureless plate; however, he retained a calamistrum. Cribellate silk appeared in the webs between instars 7 and 8, first lining the retreats or incorporated in the tangle above the sheet, and ultimately in the sheet itself in an orb-like spiral radiating out from the retreat, replacing main support lines, then filling in the sheet in subsequent instars (Figs. $6 \&$ 7). Mostly thick cribellate lines were observed in the web, with some seemingly thinner and other 'combed out' areas filling in the webs (Fig. 6C, D). The cribellum appeared functional (fully developed) in instar 7. The calamistrum appeared functional between instars 5 and 6 , during which little body growth occurred (Table 1, Fig. 4).

Second instar spiderlings did not possess a cribellar platelike structure or any precursors to functional spigots, nor did they have a calamistrum or any type of modified setae on metatarsus IV (Mallis-Alfaro, Miller \& Griswold, unpublished data). Third instar spiders possessed a single row of stout curved setae as a calamistrum and a small cribellum. Despite cribellar spigots present from third instar onward to adult (instars 11/12), and active expansion of the spigot field on the cribellum from instar to instar (Mallis-Alfaro, Miller \& Griswold, unpublished data), functionality did not seem to occur until the appearance of cribellate silk in the eighth instar. Similarly, the calamistrum expanded from a single row of setae to an oval shaped patch in the sixth instar that appeared as in the adult. Under the dissecting microscope, the cribellum appeared as a pseudobipartite plate from the third instar onward. There was a single cribellar plate, but two separate spinning fields of cribellar spigots in third and subsequent instars (Mallis-Alfaro, Miller \& Griswold, unpublished data).

To comb the cribellate silk out, spiders crossed both the 'combing leg' (leg IV) and the 'supporting leg' (other leg IV) and moved them synchronously as a single unit, using swift and sharp anterior to posterior movements. The tarsus of the combing leg IV rested on the lower half of the metatarsus on the supporting fourth leg. The same combing legs were used to complete each cribellate silk segment being laid down. Spiders tended to switch combing legs between cribellate lines.

Ontogenetic changes in web structure: Second instar spiderlings emerging from the egg sac did not construct individual webs. Instead they remained in the maternal retreat on a molting web spun collectively by all spiderlings. The molting web was comprised of thin drag lines with no adult silk contributions; however, movement onto and throughout the mother's web was possible. Third instars began to disperse from the maternal web to form individual webs. In three cases, two in the field, one in the lab, some formed a second collective web separated from the mother's retreat in the tangle scaffolding. In the webs of third instar spiderlings, the

Table 1.- Instar growth data, using the averages of 2-3 spiderlings and the standard measures of carapace length and width, tibia I length and width, femur I length and width and body length (all in $\mathrm{mm}$ ). In order to calculate the relative percent growth from instar to instar the same equation as Barrantes \& Madrigal-Brenes (2008) was used to calculate relative percent growth from instar to instar: [(Tibia I InstarN - Tibia I InstarN-1)/Tibia I InstarN-1]* 100 (Standard deviations not listed here)

Percentage Change Between Instars

\begin{tabular}{|c|c|c|c|c|c|c|c|}
\hline Instar & Carapace Length & Carapace Width & Tibia I Length & Tibia I Width & Femur I Length & Femur I Width & Body Length \\
\hline 2 to 3 & 48.68 & 34.62 & 102.25 & 41.18 & 94.12 & 71.43 & 35.73 \\
\hline 3 to 4 & 37.17 & 32.57 & 74.44 & 33.33 & 63.64 & 8.33 & 39.88 \\
\hline 4 to 5 & 23.55 & 25.00 & 33.44 & 34.38 & 26.54 & 48.72 & 24.44 \\
\hline 5 to 6 & 3.92 & 5.52 & 27.92 & 16.28 & -0.49 & 0.00 & 12.87 \\
\hline 6 to 7 & 24.37 & 24.18 & 21.83 & 10.00 & 32.11 & 18.97 & 25.10 \\
\hline 7 to 8 & 8.28 & 22.89 & 11.64 & 9.09 & 30.80 & 42.03 & 19.90 \\
\hline 8 to 9 & 57.46 & 30.62 & 33.88 & 65.00 & 32.20 & 54.08 & 35.47 \\
\hline 9 to 10 & 12.68 & 22.62 & 17.32 & 20.20 & 18.56 & 25.17 & 9.84 \\
\hline 10 to 11 & 17.67 & 13.77 & 25.24 & 25.21 & 23.98 & 16.40 & 19.98 \\
\hline
\end{tabular}




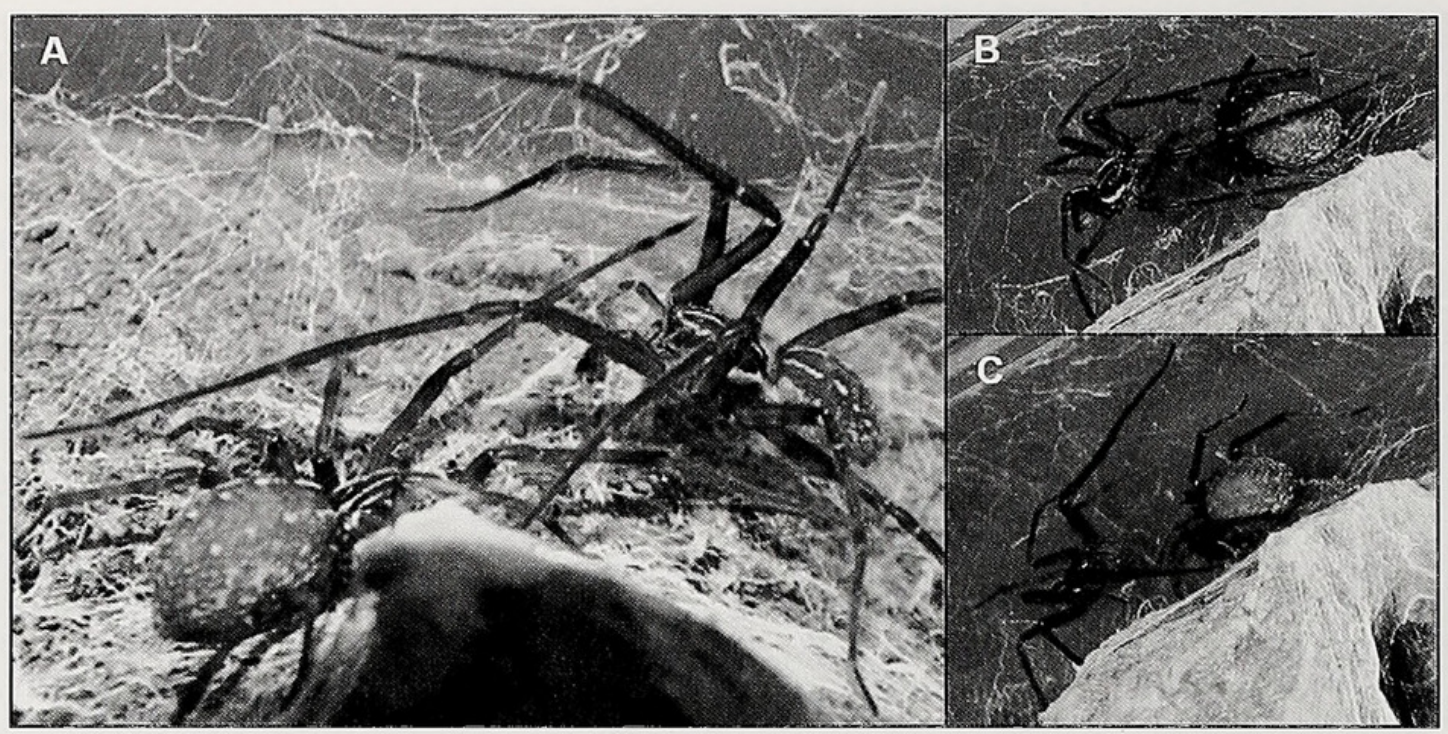

Figure 8A-C.-Courtship behaviors. A. Male strumming the web and stroking the female. B. Male stroking the female, female passive. C. Male stilting behavior.

beginnings of basic elements of adult webs were apparent with spiders forming small funnel retreats, followed by a very small sheet and tangle lines in the fourth instar (Fig. 6A, B). Retreats were either located in the middle or at one side of the web. Web complexity and size increased from one instar to the next, including multiple retreat entrances, sheet expansion and additional tangle lines (Fig. 6).

Cribellate silk did not appear in the web until instar 8 . Nearly simultaneously, cribellate lines were observed in the retreat, along with an orb-like spiral in the sheet. This was followed in later instars with heavy or thick cribellate lines in the tangle that eventually covered the majority of the web in the eleventh or penultimate instar, giving the webs a fuzzy appearance. Of the three randomly selected spiders measured for morphological growth and web ontogeny, two were penultimate males and one penultimate female. These males actively maintained their webs and laid down cribellate lines.

The twelfth instar, or adult stage, saw changes in male web use. Males were observed or collected outside of webs or in female retreats in the field. Males in their lab containers laid down a circular sheet-like web composed of dragline silk. Females continued to lay down cribellate lines on their webs and tangle scaffolding until egg sac production. In the laboratory, most adults took refuge under the sheet, instead of maintaining a retreat. This was apparently due to the artifact of the short square containers used to house the spiders in the lab colony. Webs in the field $(n>100)$ had a much more vertical stratification and multidimensional structure compared to those in the lab.

Egg sac construction: Egg sacs in the field $(n>10)$ were similar to those constructed in the lab $(n>20)$ (Fig. 3). Females constructed egg sacs in a stereotypical pattern $(n>$ 20). First, they erected a hammock-like structure, with three to four attachments at the ends to the top and sides of the container (or retreat if in the field) $(n>10)$ (Fig. 3A). Next, they added silk to form a much thicker central disc at the center of the hammock, followed by a spherical bowl underneath this disc. All of this was done while hanging upside-down. They seemingly sealed the disc to the bowl, then while hanging upside down, directly below the bowl, deposited eggs and fluids into the bowl structure. Afterwards, they laid silk over the entire bowl, reinforcing it (Fig. 3A), and then added cribellate silk lines that eventually covered the entire egg sac, completely covering it section by section. Lastly, females took pieces of the substrate in their chelicerae and placed them against the cribellum silk where they adhered (Fig. 3B), presumably serving as camouflage for the egg sac (Fig. 3B). Egg sacs were constructed singly or in pairs, about $1-2$ weeks apart. Virgin females in the lab occasionally constructed egg sacs and deposit unfertilized eggs $(n>10)$.

Courtship behavior. - Courtship began with the male orienting toward the female. Typically, in the lab, orientation by the male was preceded by preening $(n=20)$, during which time the male cleaned his palps and first two, or sometimes three, pairs of legs between his chelicerae. At this time, the majority of setae on the legs were fully visible and erect (see video S1, online at http://dx.doi.org/10.1636/JoA0S-15-004.S1). Once oriented toward the female, likely through vibratory cues, the male shook his abdomen while plucking the web with his first and second pairs of legs (Fig. 8A, see also video S2, online at http://dx.doi.org/10.1636/JoA0S-15-004.S2). If receptive $(n=$ 16), the female generally responded by tapping the web with her legs I and sometimes legs II. If not receptive, the female lifted the web around her with all four pairs of legs and forcefully pushed the web downward, as though shaking out a rug. If the female tapped, the male paused, then approached her and strummed the web and stroked her carapace and abdomen with his first pair of legs, which are much longer than those of the female (Fig. 8B). He interrupted stroking for variable periods to shake his abdomen. Sometimes the female tapped or plucked in response, sometimes repeatedly. Eventually ( $n=35$ ), the male 'stilted' up, standing as tall as physically possible on all four pairs of legs, and shook his abdomen, typically above the female carapace (Fig. 8C, see also video S2, online at http://dx.doi.org/10.1636/ JoA0S-15-004.S2). He did this stilting and shaking sequence up to three to four times. If she remained still, he deposited a 'bridal veil' of silk across the female's carapace and legs. This 
was not a restraint, as the female could easily break the lines. If the female was receptive $(n=16)$, she exposed her epigynum by laying nearly completely on her side while the male silked the bridal veil (see video $\mathrm{S} 3$, online at http://dx.doi.org/10. 1636/JoA0S-15-004.S3). As the male continued to stroke her, he gathered her legs in towards her body with his long first pair of legs. The male then copulated, using his left palp to transfer sperm into the opening of the left spermatheca and vice versa. He did this while leaning across and over the female. Coupling lasted several seconds, and the male appeared to hook the female's epigynum with the RTA or median apophysis of his partially inflated palp. When the palp engaged, the hematodocha rapidly expanded once and then deflated, which took less than a second once the embolus was engaged (see video S4, online at http://dx.doi.org/10.1636/ JoA0S-15-004.S4). Typically, both parties immediately moved rapidly apart. In a few instances $(n=3)$, the female and male slowly separated a short distance and then resumed courtship, but the majority of interactions were characterized by a rapid, dramatic separation. On several occasions, the bridal veil sequence was repeated three or more times before successful copulation occurred. The female slowly broke the silk veil and the male would then re-approach her with web strumming and carapace stroking. There was a total of 35 documented interactions; 24 were initial pairings ( $n=16$ copulations with single spermatheca), 11 reintroductions or subsequent interactions ( $n=6$ copulations, 5 rejections). Two subsequent exposures led to multiple copulations $(n=4)$ with alternation between right and left sides each insertion. An extended courtship sequence which led to two copulations is presented in supplementary materials (see video S5, online at http://dx. doi.org/10.1636/JoA0S-15-004.S5).

Males of $T$. perfuga did not possess epiandrous spigots (Mallis, unpublished SEM data) and, therefore, may load the palps with sperm and seminal fluid deposited on the web. No observations were made of males constructing a sperm web or priming the palps. While courting, however, both male palps were partially expanded. The male did preen at times just after or between copulations if left in with the female, cleaning the palps and first, second and at times even the third pair of legs with his chelicerae. No stridulatory mechanisms, such as a file, were observed on the abdomen or carapace of adult male $T$. perfuga specimens.

In the initial 24 pairings, 16 females were receptive, 6 were not receptive, and 4 males did not court. Subsequent exposures ( $n=11)$ of females (both mated and not) using the same $(n=7)$ or different males $(n=4)$ resulted in more successful courtships with some pairs $(n=6)$ copulating multiple times (up to four times before removal of the male or the female retreated or became non-receptive. Females with egg sacs $(n=2)$ were not receptive to courtship, and either ignored the male $(n=1)$ or non-aggressively drove them from the web $(n=1)$. All virginal females had "plugs" prior to courtship encounters and these plugs generally appeared soon after molting to adulthood. One female was examined under the dissecting scope, post-copulation, and had a plug on left side (non-insertion) and no plug on the right (successful copulation). However, within a day of copulation, a plug appeared on the right side. All mated females had sclerotized plugs with the same appearance as the epigynal plugs observed in virgin females.

\section{DISCUSSION}

Life history.-While $T$. perfuga took 9 - 12 molts to reach adulthood, smaller numbers can be seen in deinopoids, such as $6-7$ instars to reach maturity after emergence in Hyptiotes cavatus (Hentz, 1847). Similar to $T$. perfuga, some Pardosa C.L. Koch, 1847 have multiple egg sacs, with at least $30+$ eggs in each and follow an approximately two-year life cycle from egg sac emergence to reproduction and death (Buddle 2000). The purported sister species of $T$. perfuga, $T$. radiata reaches maturity in 9 instars ( 8 molts) for males and 10 instars $(9$ molts) for females. The time to reach adulthood was similar to that observed in the lab for $T$. perfuga: approximately 187 days for males and 229 days for females (Barrantes \& Madrigal-Brenes 2008)

Growth.- Whereas the overall growth from second instar to adulthood was over $1000 \%$ for some structures, the amount of growth varied between different instars. Despite a small sample size and, therefore, a lack of statistical testing, there appears to be less relative growth or slower growth rate between instars 5 and 6 than any other stage. This warrants further study and may be due to more energy invested in developing structures such as the calamistrum (instars 5 and 6) and cribellum (instars 7 and 8 ) becoming functional (Table 1, Fig. 4) than to morphological growth. Interestingly, Barrantes \& Madrigal-Brenes (2008) do not report any apparent slowing of growth between instars, particularly the seventh instar when cribellate silk first appears in the webs of $T$. radiata.

Allometric growth occurs between the penultimate and adult molts in leg $\mathrm{I}$ of males, as has also been observed in $T$. radiata (Barrantes \& Madrigal-Brenes 2008). Similarly, in Pisaurina mira (Walckenaer, 1837), mature males have longer legs relative to the overall body size than adult females, particularly the first pair of legs (Anderson \& Hebets 2016). Anderson and Hebets (2016) attribute this to allometry potentially driven by sexual selection. This is similarly hypothesized by Barrantes \& Madrigal-Brenes (2008) for $T$. radiata, as in the field, males were collected on or near female webs, suggesting males abandon their webs in search of females, as we suspect for $T$. perfuga. They proposed that longer legs lead to larger step sizes to bridge the distances between male and female webs or to escape cannibalistic females; however, they did not associate the longer pair of legs with courtship behavior or explicitly with sexual selection as a possible mechanism for the allometry in Leg I (Barrantes \& Madrigal-Brenes 2008).

Ontogeny of cribellum, calamistrum and cribellate silk use.The combing behavior for production of cribellate silk lines is similar to that reported for the closely related $T$. radiata (Eberhard 1988). Individual spiders varied in their favored use of the right or left leg for combing (Mallis, pers. obs.). Some switched combing legs between one line and the next. Despite the physical presence of a cribellum and a partial to full calamistrum, cribellate silk does not appear until the eighth instar. This is interesting, as many zoropsid spiders have varied use of cribellate silk throughout their life cycles (Lehtinen 1967; Griswold et al. 2005). In the closely related $T$. radiata, the apparent non-functional status of the cribellum 
and calamistrum in early instars is suggested by the lack of cribellate silk in the web until the seventh instar (Barrantes \& Madrigal-Brenes 2008). This was speculated to be due to the energetic costs of producing cribellate silk, or a reemergence of a plesiomorphic condition (Barrantes \& Madrigal-Brenes 2008). In Hyptiotes cavatus, newly emerged second instars also lacked a functional cribellum and calamistrum and did not form a web, but simply hung by a single line until molting to the third instar (Opell 1982).

Ontogenetic changes in web structure.-Silk played a role in many facets of life for $T$. perfuga, from foraging and shelter, to constructing egg sacs and in courtship. Early instar webs had many characteristics of adult webs, but on a smaller, simpler scale and without cribellate silk (Fig. 6). These are acquired in the following order: basic retreats; small sheets; and knockdown lines. At the eighth instar, cribellate silk appeared in an orb-like spiral in the sheet, and subsequently throughout the web structure (Figs. 6C, D \& 7). The lack of retreats in lab spiders was likely due to the artifact of being in the lab in a small container, as most field-caught or observed spiders actively used retreats at all life stages (Mallis, pers. obs.). Male $T$. perfuga lose functionality of the cribellum in adulthood. Females line the sheets, edges of their web and tangle with cribellate silk, and maintain the webs until egg sac production. Cribellate silk is not only used for prey capture, but also likely plays a role in courtship, propagating male and female acoustic signaling (see Courtship below).

In the web ontogeny study of $T$. radiata, Barrantes \& Madrigal-Brenes (2008) reported that in the field, second instar spiderlings did construct a collective molting web inside the mother's retreat and dispersed after molting to the third instar, as in $T$. perfuga. In the lab, second instars removed immediately after emergence from the egg sac did not readily spin a web individually (Barrantes \& Madrigal-Brenes 2008). Third instar $T$. radiata constructed a dense horizontal sheet with retreats either below or above the sheet covered by tangle lines. Webs were expanded through subsequent instars. Most importantly, the seventh instar is when cribellate silk lines are observed in the tangle and sheet of the web, but the authors do not indicate in what pattern it was observed (Barrantes \& Madrigal-Brenes 2008).

Similar to $T$. perfuga, the first capture webs of Hyptiotes cavatus in the form of a horizontal orb are constructed in the third instar, and subsequently become a cribellate triangular slice of an orb held tautly by the spider as the hub itself (Opell 1982). Males also ceased web production or maintenance in adulthood (Opell 1982). This has also been demonstrated in another uloborid, Uloborus diversus Marx, 1898, where second instar webs were horizontal orbs, without cribellate spiral silk (Eberhard 1977). Adult male Uloborus lack a functional cribellum and their web structure, if any, was similar to a second instar web (Eberhard 1977). In the ecribellate modified orb web araneioids, similar ontogenetic patterns are observed with early instars spinning vertical sticky orbs and adults using modified webs (Eberhard 1985, 1986). In the communal araneid, Cyrtophora moluccensis (Doleschall, 1857), second instar spiderlings formed a nursery web, similar to the collective molting web of $T$. perfuga, while adults had communal webs which consisted of individual orbs (Berry 1987).
Deinopoidea (cribellate horizontal orb-weavers) are more closely related to the RTA clade than to the Araneioidea (viscous silk orb-weavers, etc.), as previously thought, making the historical "Orbiculariae" paraphyletic (Bond et al. 2014; Fernandez et al. 2014; Garrison et al. 2016). The orb web is considered plesiomorphic for the deinopoid Uloboridae, and the modified cribellate webs of Hyptiotes Walckenaer, 1837 (triangular orb, spider as the hub) and Miagrammopes O.P.Cambridge, 1869 (single capture thread) as derived or apomorphic traits (Opell 1982). Given these recent phylogenetic discoveries in the evolutionary history of spiders, one would expect to find remnants of orb-weaving behavior or silk use in members of the RTA clade (Agnarsson et al. 2013). Tengella spiders are members of the RTA clade, but, as demonstrated by the spiral pattern of cribellate silk, still exhibit some deinopoid orb-weaving behavior. This is consistent with the recent studies reporting Deinopoidea ancestor to the RTA clade, and the ecribellate "Orbiculariae" as sister to the Deinopoidea + RTA clade (Agnarsson et al. 2013; Bond et al. 2014; Fernandez et al. 2014; Garrison et al. 2016).

The initial orb-like spiral of cribellate silk only occurred across instar 8 (Fig. 7). Without a web ontogeny study, these behavioral and structural characters that reflect the deinopoid and orb web ancestry would have been missed. Using $T$. perfuga as a focal study system, it would be of particular interest to move from a web ontogeny study to a comparative study of silk spigot ontogeny across cribellate silk users including the former Orbiculariae and the RTA clade. A complete spigot ontogeny dataset of $T$. perfuga is forthcoming and a phylogenetic comparative analysis of spigot ontogeny data for several species is ongoing. These studies can further elucidate ancestral orbicularian traits, such as the cribellate spiral reported here in Tengella, in both cribellate and noncribellate silk using spiders from the RTA clade.

Egg sac construction. - Camouflaging of the egg sac by the female and tolerance of second instars is recorded in numerous spider clades, such as the tetrablemmid Monoblemma muchmorei Shear, 1978 (Edwards \& Edwards 2006). In T. radiata, both $\mathrm{lab}$ and field observations reported similar camouflage techniques and placement of the egg sac by the female in her retreat (Barrantes \& Madrigal-Brenes 2008).

Courtship behavior.-Tengella perfuga has similar mating behaviors to those reported for $T$. radiata (Barrantes 2008), such as the male abdomen shaking and approach, as well as the strumming of the female web. Females, as in $T$. perfuga, assumed a passive position on their sides, exposing the epigynum to the male (Barrantes 2008). Similar broader descriptive phases could be identified as in Barrantes (2008). These include (1) male preening and orientation to female, (2) courtship performance, and (3) copulation. Whereas the basic steps tended to follow the same order, there were some notable differences. Female responses to the initial courtship of the male involved plucking or strumming with legs I and II, whereas $T$. radiata females used their palps (Barrantes 2008). Tengella radiata males had a rocking behavior while stilting (Barrantes 2008), whereas $T$. perfuga males remained still and, rather than rocking, either shook their abdomen or strummed the web. The process of male courting, female strumming response, and male advancement towards the female described 
for $T$. radiata by Barrantes (2008) is similar to that observed here in $T$. perfuga. Whereas Barrantes (2008) observed female attack behavior to repel male suitors, that kind of aggression was not observed in the $T$. perfuga females in the lab. If a lunge had occurred, no contact was made with the male and typically legs I and chelicerae were not outstretched as though attacking (Mallis, pers. obs.). The male position during copulation was different than that reported for $T$. radiata, where male and female ventral surfaces are positioned parallel to each other and touching while facing in opposite directions (Figs. 3 \& 4 in Barrantes 2008). Tengella perfuga males instead reach across and over the female dorsum to access the epigynum typically while facing nearly perpendicularly with the female. At times, due to web constraints, they were positioned parallel to each other. Palpal insertion and "flubs," defined by Barrantes (2008) as rapid scraping motions of the palp or failed embolus insertion attempts in $T$. radiata, were similar in $T$. perfuga. For example, once the palp successfully engaged, the hematodocha expanded once, lasting less than one second (Barrantes 2008). Also as in T. radiata, if multiple successful copulations were allowed to proceed, $T$. perfuga females would expose the alternating side for copulation (Barrantes 2008). Sometimes female $T$. perfuga did not accept further copulation attempts and males were removed from the containers.

The most notable and obvious difference between these two closely related species was the lack of a bridal veil in $T$. radiata, as Barrantes (2008) never made mention of this in his courtship study. It may be that males did employ this behavior; it was just not reported in the two courtship encounters of the study. Anecdotally, the first author collected $T$. radiata in Nicaragua $(2012)$ for similar purposes, but was unable to get a viable colony established. She introduced a male $T$. perfuga to a female $T$. radiata who accepted his courtship advances, including a heavy bridal veil, and allowed him to copulate. Although an egg sac was produced, it was non-viable (Mallis, pers. obs.). While female $T$. radiata were not reported to end courtship and/or copulation by breaking out of the bridal veil as $T$. perfuga, the movements of the legs to pull themselves back to standing on the sheet as reported by Barrantes (2008), were similar to those of breaking out of the veil to stand in $T$. perfuga.

Similar overall mating behaviors have been observed not only in $T$. radiata, which was selected for study because it is a cribellate relative of the Lycosoidea, but also in closely related lycosoids and agelenoids (Stratton et al. 1996; Huber 1998; Barrantes 2008). While courting a female, Pisaurina mira males used their legs to help wrap her with silk before and during copulation (Anderson \& Hebets 2016). Consequently, males typically with longer forelegs (Leg I), who could wrap females, had increased sperm transfer and a lower likelihood of falling prey to cannibalism, suggesting some form of sexual selection occurred (Anderson \& Hebets 2016). Many araneid males also employed a plucking or strumming of the web behavior (i.e., Berry 1987).

While further study is needed, the potential lack of choosiness on the part of females was not very surprising because in the field, males must wander to find females and encounter rates could be inherently low at some field sites. Also, several virginal females, collected in the field or reared in the lab, had epigynal plugs prior to mating (Mallis, pers. obs.). While this has never been reported before in a spider, it is not entirely surprising, as some studies, particularly with Leucauge White, 1841 spiders, have found that females participate in producing a mating plug both during and after copulation (Aisenberg \& Barrantes 2011). Therefore, it would not be a stretch to consider females producing an epigynal plug prior to copulation, which is a very novel observation. It is possible that the consistent behavior of flubs or 'scraping' by the male palp prior to insertion was an effort to remove the plug and that played a role in female choice. Given their relative ease of rearing and large size, combined with variable mating behaviors and other attributes, spiders of the genus Tengella lend themselves well as a model system for both sexual and silk use evolution in spiders.

\section{ACKNOWLEDGMENTS}

The authors would like to thank two anonymous reviewers for their insightful input in managing and editing this manuscript. We thank Dr. Jean-Michel Maes for his assistance with travel to and permitting in Nicaragua and collecting live spiders in order to establish our lab colony. We would also like to thank Dr. Sandra Brantley for her review and editorial suggestions for this manuscript. We thank Matthew Biggs and Matthew Leister for their assistance with lab colony maintenance, care and courtship observations. Ms. Mallis would like to thank Dr. Charles Griswold for his discussion and encouragement to re-examine the web ontogeny data and observations for evidence of orbicularian traits. Specimens were collected in Nicaragua under Autorización Especial DGPN / DB - 09 - 2012 and DGPN / DB - 006 - 2014 from Carlos Ramiro Mejía, Director of Biodiversity, MARENA of Nicaragua. Portions of this project were supported by NSF grant DEB-0845984 (K.B. Miller, PI), as well as Grove Scholarship and Graduate Research Allocation Committee grants through the University of New Mexico Department of Biology (R.E. Mallis).

\section{LITERATURE CITED}

Aisenberg, A. \& G. Barrantes. 2011. Sexual behavior, cannibalism, and mating plugs as sticky traps in the orb weaver Leucauge argyra (Tetragnathidae). Naturwissenschaften 98:605-613.

Agnarsson, I., J.A. Coddington \& M. Kuntner. 2013. Systematics: Progress in the study of spider diversity and evolution. Pp. 58-111. In Spider Research in the $21^{\text {st }}$ Century: Trends \& Perspectives. (D. Penney, ed.). Siri Scientific Press, Manchester, U.K.

Anderson, A.G. \& E.A. Hebets. 2016. Benefits of size dimorphism and copulatory silk wrapping in the sexually cannibalistic nursery web spider, Pisaurina mira. Biology Letters 12:20150957. Online at http://dx.doi.org/10.1098/rsbl.2015.0957

Barrantes, G. 2008. Courtship behavior and copulation in Tengella radiata (Araneae, Tengellidae). Journal of Arachnology 36:606 608.

Barrantes, G. \& R. Madrigal-Brenes. 2008. Ontogenetic changes in web architecture and growth rate of Tengella radiata (Araneae, Tengellidae). Journal of Arachnology 36:545-551.

Barrantes, G. \& W.G. Eberhard. 2010. Ontogeny repeats phylogeny in Steatoda and Latrodectus spiders. Journal of Arachnology 28:484 494.

Berry, J.W. 1987. Notes on the life history and behavior of the communal spider Cyrtophora moluccensis (Doleschall) (Araneae: 
Araneidae) in Yap, Caroline Islands. Journal of Arachnology 15:309-319.

Blackledge, T.A., J.A. Coddington \& I. Agnarsson. 2009a. Fecundity increase supports adaptive radiation hypothesis in spider web evolution. Communicative \& Integrative Biology 2:459 463.

Blackledge, T.A., N. Scharff, J.A. Coddington, T. Szüts, J.W. Wenzel, C.Y. Hayashi et al. 2009b. Reconstructing web evolution and spider diversification in the molecular era. Proceedings of the National Academy of Sciences, USA 106:5229-5234.

Bond, J.E., N.L. Garrison, C.A. Hamilton, R.L. Godwin, M. Hedin \& I. Agnarsson. 2014. Phylogenomics resolves a spider backbone phylogeny and rejects a prevailing paradigm for orb web evolution. Current Biology 24:1-7.

Buddle, C.M. 2000. Life history of Pardosa moesta and Pardosa mackenziana (Araneae, Lycosidae) in Central Alberta, Canada. Journal of Arachnology 28:319-328.

Eberhard, W.G. 1977. The webs of newly emerged Uloborus diversus and of a male Uloborus sp. (Araneae, Uloboridae). Journal of Arachnology 4:201-206.

Eberhard, W.G. 1985. The 'sawtoothed' orb of Eustala sp., with a discussion of the ontogenetic patterns of change in web design in spiders. Psyche 92:105-118.

Eberhard, W.G. 1986. Ontogenetic changes in the web of Epeirotypus sp. (Araneae, Theridiosomatidae). Journal of Arachnology 14:125128.

Eberhard, W.G. 1988. Combing and sticky silk attachment behaviour by cribellate spiders and its taxonomic implications. Bulletin of the British Arachnological Society 7:247-251

Eberhard, W.G., N.I. Platnick \& R.T. Schuh. 1993. Natural history and systematics of arthropod symbionts (Araneae; Hemiptera; Diptera) inhabiting webs of the spider Tengella radiata (Araneae, Tengellidae). American Museum Novitates 3065:1-17.

Edwards, R.L. \& A.D. Edwards. 2006. Life history and ecology of the armored spider Monoblemma muchmorei (Araneae, Tetrablemmidae). Journal of Arachnology 34:599 609.

Fernández, R., G. Hormiga \& G. Giribet. 2014. Phylogenomic analysis of spiders reveals nonmonophyly of orb weavers. Current Biology 24:1-6.

Garrison, N.L., J. Rodriguez, I. Agnarsson, J.A. Coddington, C.E. Griswold, C.A. Hamilton, et al. 2016. Spider phylogenomics: untangling the Spider Tree of Life. PeerJ 4: e1719. Online at doi 10. 7717 peerj. 1719

Griswold, C. E., M.J. Ramírez, J.A. Coddington \& N. I. Platnick. 2005. Atlas of phylogenetic data for entelegyne spiders (Araneae:
Araneomorphae: Entelegynae) with comments on their phylogeny. Proceedings of the California Academy of Sciences 56:1-324.

Hawthorn, A.C. \& B.D. Opell. 2002. Evolution of adhesive mechanisms in cribellar spider prey capture thread: evidence for van der Waals and hygroscopic forces. Biological Journal of the Linnaean Society 77:1-8.

Huber, B.A. 1998. Spider reproductive behaviour: a review of Gerhardt's work from 1911-1933, with implications for sexual selection. Bulletin of the British Arachnological Society 11:81-91.

Lehtinen, P.T. 1967. Classification of the cribellate spiders and some allied families, with notes on the evolution of the suborder Araneomorpha. Annales Zoologici Fennici 4:199 468.

Leister, M., R. Mallis \& K. Miller. 2013. The male of Tengella perfuga Dahl, 1901 with re-description of the female and comparisons with T. radiata (Kulczynski, 1909) (Araneae: Tengellidae). Zootaxa 3709:185-199.

Opell, B.D. 1982. Post-hatching development and web production of Hyptiotes cavatus (Hentz) (Araneae, Uloboridae). Journal of Arachnology 10:185-191.

Pechmann, M., S. Khadjeh, F. Sprenger, \& N.-M. Prpic. 2010. Patterning mechanisms and morphological diversity of spider appendages and their importance for spider evolution. Arthropod Structure \& Development 39:453-467.

Platnick, N.I. 2009. A review of the spider genus Tengella (Araneae: Tengellidae). Contributions to Natural History 12:1071-1080.

Polotow, D., A. Carmichael \& C.E. Griswold. 2015. Total evidence analysis of the phylogenetic relationships of Lycosoidea spiders (Araneae, Entelegynae). Invertebrate Systematics 29:124-163.

Raven, R. J. \& K. Stumkat. 2003. Problem solving in the spider families Miturgidae, Ctenidae and Psechridae (Araneae) in Australia and New Zealand. Journal of Arachnology 31:105-121.

Raven, R.J. \& K. Stumkat. 2005. Revisions of Australian groundhunting spiders: II: Zoropsidae (Lycosoidea: Araneae). Memoirs of the Queensiand Museum 50:347-423.

Spagna, J. C. \& R. G. Gillespie. 2008. More data, fewer shifts: Molecular insights into the evolution of the spinning apparatus in non-orb-weaving spiders. Molecular Phylogenetics and Evolution 46:347-368.

Stratton, G.E., E.A. Hebets, P.R. Miller \& G.L. Miller. 1996. Pattern and duration of copulation in wolf spiders (Araneae, Lycosidae). Journal of Arachnology 24:186-200.

Manuscript received 8 December 2015, revised 10 November 2016. 


\section{$2 \mathrm{BHL}$ Biodiversity Heritage Library}

Mallis, Rachael E and Miller, Kelly B. 2017. "Natural history and courtship behavior in Tengella perfuga Dahl, 1901 (Araneae: Zoropsidae)." The Journal of arachnology 45(2), 166-176. https://doi.org/10.1636/15-004.1.

View This Item Online: https://www.biodiversitylibrary.org/item/274742

DOI: https://doi.org/10.1636/15-004.1

Permalink: https://www.biodiversitylibrary.org/partpdf/289900

\section{Holding Institution}

Smithsonian Libraries

\section{Sponsored by}

Biodiversity Heritage Library

\section{Copyright \& Reuse}

Copyright Status: In Copyright. Digitized with the permission of the rights holder

Rights Holder: American Arachnological Society

License: https://creativecommons.org/licenses/by-nc-sa/4.0/

Rights: http://www.biodiversitylibrary.org/permissions/

This document was created from content at the Biodiversity Heritage Library, the world's largest open access digital library for biodiversity literature and archives. Visit BHL at https://www.biodiversitylibrary.org. 